\title{
Contribution of (factors) cooking water, raw rice, and traditional cooking method on cooked rice arsenic level
}

\author{
D. Chatterjee \& U. Mandal \\ Department of Chemistry, University of Kalyani, Kalyani, Nadia, West Bengal, India
}

\begin{abstract}
Rice consumption has now been established as a well-recognized exposure source of arsenic for many subpopulations. The aim is to investigate the various factors that might exert control on the final arsenic content in cooked rice following the indigenous cooking practice pursued by the rural villagers of West Bengal. It was found that the use of arsenic-rich groundwater for cooking elevates the arsenic concentration in cooked rice (up to $162 \%$ than the raw rice), making the rural population of West Bengal particularly vulnerable to arsenic poisoning through rice consumption. Results of our study show that for the cooking method employed, rice variety, background arsenic concentration in raw rice and cooking water arsenic concentration are important predisposing factors that direct the accumulation of arsenic in cooked form.
\end{abstract}

\section{INTRODUCTION}

In the last few decades, a lot of articles have been published which show that millions of people worldwide are exposed to high levels of arsenic (As) from drinking contaminated water (Nriagu et al., 2007). The major point of concern is that rice is the dominant food source for the world population, particularly in developing Asian countries, where an average of $72.8 \%$ of the daily calorie intake per capita are provided from rice intake. Since rice has the potential to accumulate more As than other food crops, rice intake has provided a facile route for As exposure (Chatterjee et al., 2010; Meharg et al., 2009). The risk posed from rice depends upon both the amount of rice consumed and the concentration of inorganic As in rice grains, moderated by gut bioavailability. In the present study, rice samples were cooked in individual households in rural Bengal affected by endemic arsenocosis, following the traditional cooking method adopted by the villagers. The use of As-free cooking water in decreasing As content in cooked rice was explored so as to evaluate the reduction in As exposure for the population.

\section{MATERIALS AND METHODS}

\subsection{Study area}

The study area is located in Chaku-danga village of Chakdaha block in Nadia district, West Bengal. The agricultural system is highly dependent upon groundwater to meet the water requirement for irrigation of crop.

\subsection{Rice cooking and sample collection}

For this study, rice was cooked in individual households following the procedure adopted by rural villagers. Generally, rice was washed 3-4 times with water and the washed rice was soaked in excess water (10-12 times the weight of raw rice) for 15-20 minutes and finally cooked. After cooking, the excess starch water (gruel) was discarded by tilting the pan against the lid. The entire cooking procedure as described above was done using the supplied Milli-Q water.

\subsection{Sample analysis}

Cooking water, raw rice, starch water, and cooked rice were analyzed for As by hydride generation atomic absorption spectroscopy (HG-AAS) (Varian AA240).

\subsection{Statistical analysis}

SPSS statistical software, version 17.0 by IBM was used for data analysis. Independent variables such as rice variety, As concentration in raw rice and cooking water were tested for multiple linear regression analysis with As content in cooked rice. Statistical significance was indicated by values of $\mathrm{p}<0.05$.

\section{RESULTS AND DISCUSSION}

Our initial baseline survey revealed that Ratna, Satabdi, Pratik, Parijat, Ranjit, Swarna are the most common rice varieties that are used by the villagers in the study area. The median As concentration in 
raw rice (uncooked) for the six rice varieties investigated in this study was $228 \mu \mathrm{g} \mathrm{kg}^{-1}$ ranging between $105-510 \mu \mathrm{g} \mathrm{kg}^{-1}$. Categorizing the collected raw rice As concentration with respect to rice varieties, it was found that Swarna had the highest grain As concentration (median: $380 \mu \mathrm{g} \mathrm{As} \mathrm{kg}{ }^{-1}$; range: $270-510 \mu \mathrm{g} \mathrm{As}$ $\mathrm{kg}^{-1}$ ) followed by Ranjit (median: $221 \mu \mathrm{g} \mathrm{As} \mathrm{kg}{ }^{-1}$; range: $206-360 \mu \mathrm{g} \mathrm{As} \mathrm{kg}^{-1}$ ), Parijat (median: $205 \mu \mathrm{g}$ As kg ${ }^{-1}$; range: $140-370 \mu \mathrm{g} \mathrm{As} \mathrm{kg}^{-1}$ ), Pratik (median: $194 \mu \mathrm{g} \mathrm{As} \mathrm{kg}{ }^{-1}$; range: $155-358 \mu \mathrm{g} \mathrm{As} \mathrm{kg}^{-1}$ ), Ratna (median: $179 \mu \mathrm{g} \mathrm{As} \mathrm{kg}^{-1}$; range: $130-235 \mu \mathrm{g}$ As $\mathrm{kg}^{-1}$ ), while Satabdi (median: $163 \mu \mathrm{g} \mathrm{As} \mathrm{kg}^{-1}$; range: 105-356 $\mu \mathrm{g} \mathrm{As} \mathrm{kg}^{-1}$ ) had the lowest As concentration. The variability and distribution of total As in the classified rice grains have been shown by Box and Whisker plot.

Studies have shown that there can be severe variation in the final As concentration in cooked rice from the initial As concentration in raw rice. This study indicates among the six rice varieties studied, Swarna variety (short bold) has the maximum As concentration compared to the other rice varieties. However, the discrepancies in As concentration with grain size is somewhat perturbed when plotted for the cooked form indicating that the As concentration in cooked rice may vary greatly from the raw rice, depending upon cooking water and pattern and rice varieties. Results of our study indicate that As in cooking water can be a very important determinant for As in cooked rice. Elevated concentration of As in cooking water can result in the influx of As in cooked rice, thereby causing an increase in As content in the cooked form. Moreover, rice variety also influences the amount of As influx in the cooked rice samples, thereby being a principal factor controlling the cooked rice As concentration. Cooking rice with water with low As concentration can therefore be seen as a "decontamination" process as it tends to leach-out As from rice grain into the gruel and thereby ultimately decreasing the As exposure from rice intake. The results confirm the findings of the past laboratory based studies which have shown reduction in As content in cooked rice following the use of low As water.

\section{CONCLUSIONS}

This study further suggests that, provided As-safe cooking water are used, the traditional cooking practice can actually be beneficial for the rural people of Bengal as the cooking procedure and the large volume of low As water enables the contaminated rice with sufficient contact time to leach As from the rice grains into the starch water, thereby food grain highly elevated with As may be made suitable for human consumption. Therefore, although strategies on decreasing the As content in raw rice grains should be promoted, As in cooked rice is the actual point of convergence for the dietary exposure for the population and attempts to limit the As in cooked rice must be taken into consideration to successfully combat the menace of As.

\section{ACKNOWLEDGEMENTS}

We would also like to thank UGC-SAP program and DST-FIST program to the Department of Chemistry, University of Kalyani.

\section{REFERENCES}

Chatterjee, D., Halder, D., Majumder, S., Biswas, A., Nath, B. Bhattacharya, P., Bhowmick, S., Mukherjee-Goswami, A., Saha, D., Maity, P.B., Chatterjee, D., Mukherjee, A. \& Bundschuh, J. 2010. Assessment of arsenic exposure from groundwater and rice in Bengal Delta Region, West Bengal, India. Water Res. 44(19): 5803-5812.

Meharg, A.A., Williams, P.N., Adomako, E., Lawgali, Y.Y., Deacon, C., Villada, A., Cambell, R., Sun, G.X., Zhu, Y.G., Feldmann, J., Raab, A., Zhao, F.J., Islam, M., Hossain, S. \& Yanai, J. 2009. Geographical variation in total and inorganic arsenic content of polished (white) rice. Environ. Sci. Technol. 43(5): 1612-1617.

Nriagu, J., Bhattacharya, P., Mukherjee, A., Bundschuh, J., Zevenhoven, R. \& Loeppert, R. 2007. Arsenic in soil and groundwater: an overview. In: Bhattacharya, P., Mukherjee, A.B., Bundschuh, J., Zevenhoven, R., Loeppert, R.H. (eds), Arsenic in Soil and Groundwater Environment. Elsevier, Amsterdam, pp. 3-60. 